ARTICLE

https://doi.org/10.1038/s41467-019-13052-1

\title{
A bio-inspired coordination polymer as outstanding water oxidation catalyst via second coordination sphere engineering
}

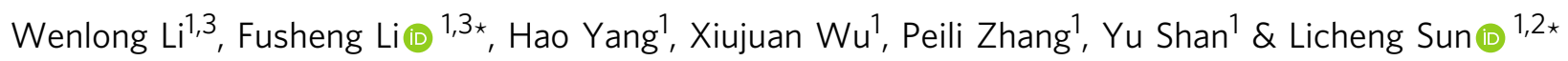

First-row transition metal-based catalysts have been developed for the oxygen evolution reaction (OER) during the past years, however, such catalysts typically operate at overpotentials $(\eta)$ significantly above thermodynamic requirements. Here, we report an iron/ nickel terephthalate coordination polymer on nickel form (NiFeCP/NF) as catalyst for OER, in which both coordinated and uncoordinated carboxylates were maintained after electrolysis. NiFeCP/NF exhibits outstanding electro-catalytic OER activity with a low overpotential of $188 \mathrm{mV}$ at $10 \mathrm{~mA} \mathrm{~cm}^{-2}$ in $1.0 \mathrm{KOH}$, with a small Tafel slope and excellent stability. The pHindependent OER activity of NiFeCP/NF on the reversible hydrogen electrode scale suggests that a concerted proton-coupled electron transfer (c-PET) process is the rate-determining step (RDS) during water oxidation. Deuterium kinetic isotope effects, proton inventory studies and atom-proton-transfer measurements indicate that the uncoordinated carboxylates are serving as the proton transfer relays, with a similar function as amino acid residues in photosystem II (PSII), accelerating the proton-transfer rate.

\footnotetext{
${ }^{1}$ State Key Laboratory of Fine Chemicals, Institute of Artificial Photosynthesis, DUT-KTH Joint Education and Research Centre on Molecular Devices, Institute for Energy Science and Technology, Dalian University of Technology, 116024 Dalian, China. ${ }^{2}$ Department of Chemistry, School of Engineering Sciences in Chemistry, Biotechnology and Health, KTH Royal Institute of Technology, Stockholm 10044, Sweden. ${ }^{3}$ These authors contributed equally: Wenlong Li, Fusheng Li *email: fusheng@dlut.edu.cn; sunlc@dlut.edu.cn
} 
T he growing global demand for energy, coupled with an increasing awareness of climate change, has motivated the development of new renewable energy conversion technologies ${ }^{1,2}$. Electrochemical water splitting to produce sustainable $\mathrm{H}_{2}$ fuel has been widely regarded as one of the most promising strategies for energy storage. The efficiency of water splitting is severely hampered by a sluggish process, that is, the oxygen evolution reaction (OER). The multi-electron and protoncoupled OER is a kinetically slow reaction, and as a result, large overpotentials are usually required, which decreases the energy conversion efficiency and hinders the practical applications of devices.

So far, significant efforts have been devoted to fabricate efficient, alternative OER catalysts. Hitherto, $\mathrm{IrO}_{2}$ and $\mathrm{RuO}_{2}$ are two benchmark OER catalysts employed for acidic electrolysis, on account of their high activity for water oxidation. However, the scarcity of Ir and $\mathrm{Ru}$ limits their large-scale application ${ }^{3}$. At the same time, extensive efforts have been taken to explore nonnoble metal catalysts with outstanding activity and stability for alkaline electrolysis. The bimetallic $\mathrm{Fe}-\mathrm{Ni}$ composites are regarded as one of the most promising alternatives in the family of OER catalysts, however, such composites operate at high $\eta$ toward the OER and the mechanistic details for the associated elemental steps are poorly understood. Because proton has a much larger mass than that of electron, slow proton/fast electron transfer will be realized ${ }^{4,5}$, and the rate of ferrying proton may determine the overall water oxidation reaction. Thence, a comprehensive understanding of the underlying mechanism of proton-coupled interfacial electron transfer process in the ratedetermining step (RDS) is vital importance for obtaining efficient OER catalysts, and a new thinking and related design of the surface active site at molecular level to accelerate the sluggish kinetics are urgently needed.

In green plants and cyanobacterial, light driven water oxidation by the oxygen-evolving complex (OEC) in PSII occurs with a high turnover frequency of $100-400 \mathrm{~s}^{-1}$ in vivo at low overpotential $(\eta<200 \mathrm{mV})^{6,7}$. The evolution of oxygen by OEC is an integrated process, not only involving the $\mathrm{Mn}_{4} \mathrm{CaO}_{5}$ cluster as catalyst, but also is assisted by other functional groups in the first and second coordination spheres, such as carboxylate and imidazole ligands from amino-acid residues of the protein backbone ${ }^{8,9}$. These electron-rich ligands strongly stabilize the high valent states of the $\mathrm{Mn}_{4} \mathrm{CaO}_{5}$ cluster and play vital roles in effective water oxidation with low overpotential7,10. Inspired by PSII, strong electron donating ligands, such as phenolate and carboxylate ligands are extensively utilized in the structures of homogeneous molecular water oxidation catalysts. Generally, the redox potentials of metal complexes can be tuned by ligand modification, and the incorporation of negatively-charged ligands into metal complexes has previously been shown to stabilize metal centers at higher oxidation states and result in complexes with significantly lower redox potentials 7,10 .

Furthermore, the presence of carboxylate ligands in the OEC is crucial for transporting the generated protons during water oxidation. For example, the amino acid residue of Asp170 has been proposed to form a hydrogen bond with a coordinated water molecule on $\mathrm{Mn}_{4} \mathrm{CaO}_{5}$ cluster ${ }^{11,12}$, and may act as an internal base for proton transfer during the $\mathrm{O}-\mathrm{O}$ bond formation 12,13 . Asp61 is also proposed serving the similar function ${ }^{14,15}$. This internal base strategy has been reported when designing molecular water oxidation catalysts, in which carboxylate or pyridine groups are employed as the internal base (proton transfer relay) for proton transfer during water oxidation ${ }^{16-18}$. These secondcoordination-sphere effects can be also introduced to the heterogeneous OER catalysts.

Inspired by the OEC structure in PSII, herein, we report a binder-free $\mathrm{Ni}-\mathrm{Fe}$ coordination polymer $(\mathrm{NiFeCP})$ prepared via an in situ electrochemical deposition method on a $\mathrm{Ni}$ foam (NF) as catalyst (NiFeCP/NF) for OER (Fig. 1). Negativelycharged carboxylate ligands were simultaneously introduced into the $\mathrm{NiFeCP}$ composites in both coordinated and uncoordinated forms, with the former expected to stabilize the high valence states of the metal centers, and the latter expected to serve as proton transfer relays in the second-coordination-sphere of the active site. To our delight, the as prepared $\mathbf{N i F e C P / N F}$ electrode exhibits excellent catalytic activity with a low onset potential of $1.41 \mathrm{~V}$ (vs. reversible hydrogen electrode, RHE), and a constantly low $\eta$ of $188 \mathrm{mV}$ to reach $10 \mathrm{~mA} \mathrm{~cm}{ }^{-2}$ in $1.0 \mathrm{M} \mathrm{KOH}$ electrolyte. The $\mathrm{pH}$-independence OER property combining with deuterium kinetic isotope effects, proton inventory and atom proton transfer studies demonstrates that the uncoordinated carboxylate groups in $\mathrm{NiFeCP}$ participate in the water oxidation reaction by serving as the proton transfer relays and contribute to the superior activity of the NiFeCP/NF catalyst toward OER.

\section{Results}

The NiFeCP/NF electrode was prepared via a repeated doublecurrent pulse chronopotentiometry (Supplementary Fig. 1). As a result of the fast reaction process during deposition, electrodeposited materials are often amorphous or possess low crystallinity, which provide opportunities to obtain a polymer comprising both coordinated and uncoordinated carboxylate ligands. The $\mathrm{Fe}^{3+}$ incorporated in Ni-based catalysts has been reported to be the key factor for high catalytic performance, although its exact role remains ambiguous ${ }^{19,20}$. The OER electrocatalytic performances of the NiFeCP/NF prepared with different Ni:Fe ratios in the electrodeposition solution were measured, as presented in the linear sweep voltammograms (LSVs) in Supplementary Fig. 2a. The prepared electrode exhibited the best catalytic activity with smallest Tafel slope

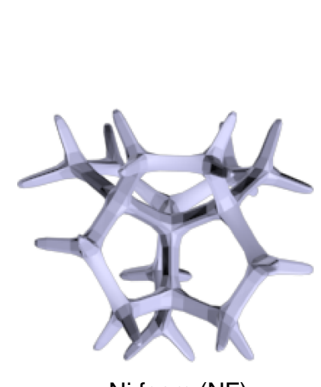

Ni foam (NF)

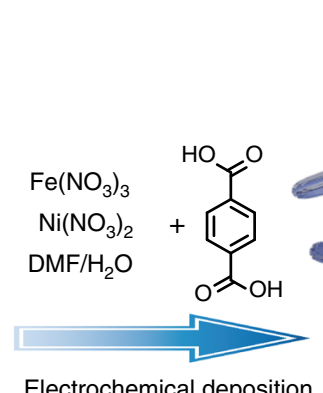

Electrochemical deposition
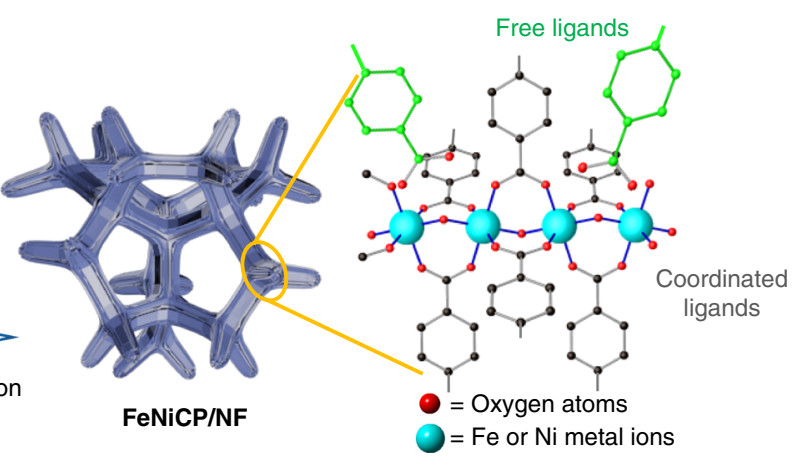

Fig. 1 Schematic illustration of the fabrication procedure of the Ni-Fe coordination polymer prepared via an in situ electrochemical deposition method on Ni foam (NF) as a working electrode (NiFeCP/NF) 

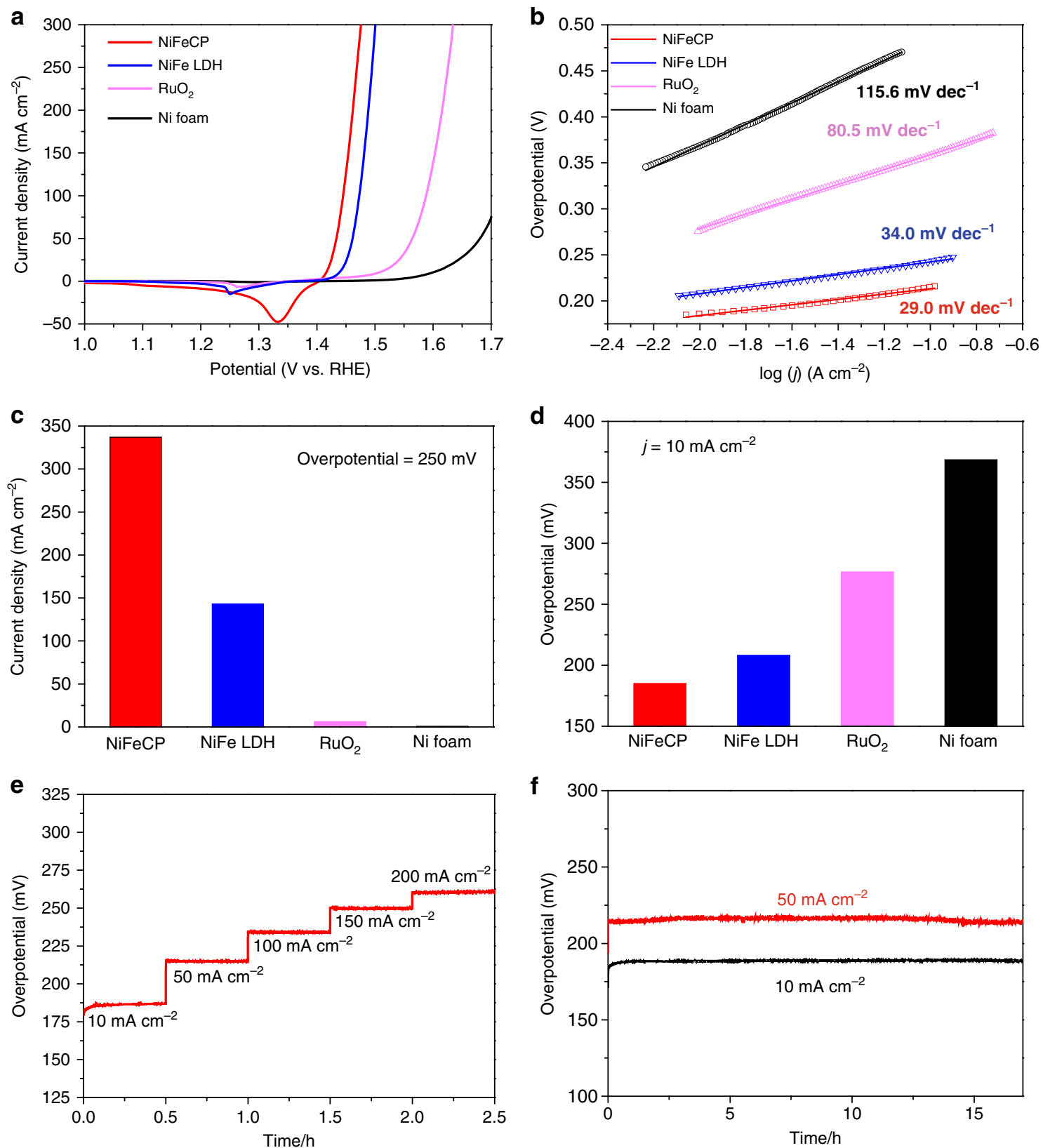

Fig. 2 Electrochemical characterizations for OER. a Linear sweep voltammetry (LSV) curves of NiFeCP/NF, NiFe $\mathbf{L D H} / \mathbf{N F}, \mathrm{RuO} / 2 / \mathrm{NF}$, and Ni foam. b NiFeCP/NF, NiFe LDH/NF, $\mathrm{RuO}_{2} / \mathrm{NF}$, and Ni foam. c Current densities at an overpotential, $\eta=250 \mathrm{mV}$, as a function of electrode type. $\mathbf{d}$ The $\eta$ required for $j=10 \mathrm{~mA} \mathrm{~cm}^{-2}$ as a function of electrode type. e Chronopotentiometric measurements of OER in $1.0 \mathrm{M} \mathrm{KOH}$ as a function of current density. f Extended chronopotentiometric measurements at $j=10 \mathrm{~mA} \mathrm{~cm}^{-2}$ and $j=50 \mathrm{~mA} \mathrm{~cm}^{-2}$ for $17 \mathrm{~h}$

(Supplementary Fig. 2b) for OER when the Ni:Fe ratio was 7:3 in the electrodeposition solution, thus, this electrode was systematically studied in this work, and abbreviated as NiFeCP/NF in this paper.

For comparison, the state-of-the-art NiFe layered double hydroxide (NiFe LDH) catalyst was prepared on $\mathrm{Ni}$ foam (NiFe LDH/NF) as previously reported ${ }^{21-23}$. The polarization curves of NiFeCP/NF, NiFe LDH/NF, $\mathrm{RuO}_{2} / \mathrm{NF}$ and nickel foam toward OER in $1.0 \mathrm{M} \mathrm{KOH}$ are shown in Fig. 2a. Among the electrodes, NiFeCP/NF electrode (the best samples) demonstrates an outstanding catalytic activity, delivers the highest current density at the same $\eta$ than the other electrodes.

In order to investigate the intrinsic activity of $\mathrm{NiFeCP} / \mathrm{NF}$ and NiFe LDH/NF electrodes, the polarization curves are normalized to the electrochemically active surface area (ECSA), respectively
(Supplementary Fig. 3). NiFeCP/NF required the much lower overpotential for the same normalized current density, for example, NiFeCP/NF achieves a $10 \mathrm{~mA} \mathrm{~cm}^{-2}$ normalized current density at $\eta=190$, while $\mathbf{N i F e} \mathbf{L D H} / \mathbf{N F}$ required an overpotential of $210 \mathrm{mV}$. This result indicated that $\mathrm{NiFeCP} / \mathrm{NF}$ displayed the better performance than that of $\mathrm{NiFe}$ LDH/NF electrode, which is because of that NiFeCP catalyst itself has a better intrinsic activity compared to that of $\mathrm{NiFe} \mathbf{L D H}$, rather than the larger specific surface area of NiFeCP/NF electrode.

Furthermore, NiFeCP/NF exhibits a remarkable low Tafel slope of $29 \mathrm{mV} \mathrm{dec}^{-1}$, while NiFe LDH/NF shows a Tafel slope of $34 \mathrm{mV} \mathrm{dec}^{-1}$ (Fig. 2b). The Tafel slope value for NiFe LDH/ $\mathbf{N F}$ is in agreement with literature reports ${ }^{21-23}$, indicating the reliability of our results. The various catalysts were further compared by a plot of their catalytic currents at a fixed $\eta$ of 
$250 \mathrm{mV}$. As shown in Fig. 2c, the NiFeCP/NF electrode delivers a current density of $337 \mathrm{~mA} \mathrm{~cm}^{-2}$, which demonstrates as 2.3, 56, and $521-$ fold increase over that of NiFe LDH/NF $(143 \mathrm{~mA}$ $\left.\mathrm{cm}^{-2}\right), \mathrm{RuO}_{2} / \mathrm{NF}\left(6.2 \mathrm{~mA} \mathrm{~cm}^{-2}\right)$, and $\mathrm{NF}\left(0.64 \mathrm{~mA} \mathrm{~cm}^{-2}\right)$, respectively. To reach a current density of $10 \mathrm{~mA} \mathrm{~cm}^{-2}$, the NiFeCP/NF electrode requires an overpotential of $188 \mathrm{mV}$, which is 22,89 , and $180 \mathrm{mV}$ lower than that of $\mathbf{N i F e ~} \mathbf{L D H} / \mathbf{N F}$ $(210 \mathrm{mV}), \mathrm{RuO}_{2} / \mathrm{NF}(277 \mathrm{mV})$, and $\mathrm{NF}(368 \mathrm{mV})$, respectively (Fig. 2d).

To test steady-state activity and durability, the NiFeCP/NF electrode was subjected to a series of chronopotentiometry experiments comprising multiple current steps in $1.0 \mathrm{M} \mathrm{KOH}$ for $0.5 \mathrm{~h}$. As shown in Fig. 2e, the corresponding required potentials are profiled when the catalytic current densities were increased from 10 to $200 \mathrm{~mA} \mathrm{~cm}^{-2}$. At an initial current density of $10 \mathrm{~mA}$ $\mathrm{cm}^{-2}$, an overpotential of $188 \mathrm{mV}$ was needed, which remained constant for the duration of the test $(0.5 \mathrm{~h})$. Thereafter, the values of overpotential were observed to increase, and maintain their stability, when the current density was increased from 50 to $200 \mathrm{~mA} \mathrm{~cm}^{-2}$. NiFeCP/NF displayed a current density of 50, 100, 150 , and $200 \mathrm{~mA} \mathrm{~cm}^{-2}$ at overpotentials of $214,234,249$, and $260 \mathrm{mV}$, respectively.

Furthermore, the durability of the $\mathbf{N i F e C P / N F}$ electrode toward OER was examined at constant current densities of 10 and $50 \mathrm{~mA} \mathrm{~cm}^{-2}$ for $17 \mathrm{~h}$. As shown in Fig. 2f, overpotentials of 188 $\mathrm{mV}$ and $214 \mathrm{mV}$ are needed to maintain the OER catalytic current densities at $10 \mathrm{~mA} \mathrm{~cm}^{-2}$ and $50 \mathrm{~mA} \mathrm{~cm}^{-2}$, respectively. The double-layer capacitance $\left(\mathrm{C}_{\mathrm{dl}}\right)$ is a positive correlation with the ECSA of the NiFeCP/NF electrode, which was measured (Supplementary Fig. 4) after 17 hours electrolysis, no obvious change of $\mathrm{C}_{\mathrm{dl}}$ has be observed compared to the NiFeCP/NF electrode before electrolysis (Supplementary Fig. 5). The amount of $\mathrm{O}_{2}$ generated by $\mathbf{N i F e C P / N F}$ and $\mathbf{N i F e} \mathbf{L D H} / \mathbf{N F}$ were measured, and Faradaic efficiencies of $98.4 \%$ and $97.8 \%$ were obtained at $j=$ $10 \mathrm{~mA} \mathrm{~cm}^{-2}$ for $\mathrm{NiFeCP/NF}$ and NiFe LDH/NF, respectively, indicating the accumulated charge passed through $\mathbf{N i F e C P / N F}$ and NiFe LDH/NF electrodes were almost quantitatively consumed for OER (Supplementary Fig. 6).

Transition metal coordination polymers such as metal-organic frameworks (Ni, Co, Fe MOFs) have been extensively studied as a new class of catalysts toward OER in alkaline solutions ${ }^{24-31}$. Unfortunately, only a few transition metal coordination polymers with low overpotential and excellent stability have been reported. Hitherto, Ni-Co bimetal organic framework nanosheets (NiCo -UMOFNs) electrode loaded on copper foam in the presence of a binder (Nafion solution) demonstrates a low onset potential of $1.39 \mathrm{~V}$ and an overpotential of $189 \mathrm{mV}$ at $10 \mathrm{~mA} \mathrm{~cm}^{-2}$ in alkaline conditions (according to LSV measurements) ${ }^{31}$. Ni-Fe bimetal two-dimensional (2D) ultrathin MOF nanosheets (NiFe-UMNs) have been reported as a catalyst for OER with $10 \mathrm{~mA} \mathrm{~cm}^{-2}$ current density at an overpotential of $260 \mathrm{mV}$ on a glass-carbon electrode $^{29}$. NiFe MOF (MIL-53) nanosheets grown in situ on $\mathrm{Ni}$ foams via a solvothermal process, presented excellent activity toward OER with $50 \mathrm{~mA} \mathrm{~cm}^{-2}$ current density at an $\eta$ of $233 \mathrm{mV}^{32}$. Interestingly, the present $\mathbf{N i F e C P / N F}$ demonstrates enhanced performance when compared with MIL-53 nanosheets grown in situ on $\mathrm{Ni}$ foam via a solvothermal process $\left(50 \mathrm{~mA} \mathrm{~cm}^{-2}\right.$ current density at an $\eta$ of $214 \mathrm{mV}$ for NiFeCP/NF). Supplementary Table 1 lists the performance of $\mathbf{N i F e C P / N F}$ in the current work and previously reported electrodes for electrocatalytic water oxidation, including coordination polymer based and inorganic material based catalysts. This comparison demonstrates that the NiFeCP/NF electrode prepared via the fast electrochemical deposition process, is clearly superior to other reported systems derived from high crystallinity methods in terms of $\eta$ and the Tafel slope.
To elucidate the structural characteristics of NiFeCP, especially the existence of uncoordinated carboxyl groups, various techniques were performed to characterize the structure of as prepared NiFeCP/NF and after OER electrochemical experiments. The electrodeposition process appeared to generate a brown film deposited on the surface of the nickel foam, however, after OER, the color of the as prepared NiFeCP/NF electrode turned black (Supplementary Fig. 7), which could change back to a brown color after rinsing with ethanol or by placing it in air over a prolonged period of time. The color changing phenomenon is similar to that observed for NiFe LDH, indicating that the following reaction occurs: $\mathrm{Ni}-\mathrm{OH} \rightarrow \mathrm{Ni}-\mathrm{OOH}$. Additionally, $-\mathrm{Ni}^{\mathrm{II} \mathrm{OH}}$ species could be present before and after OER in the presence of NiFeCP/NF. The X-ray powder diffraction (XRD) pattern (Supplementary Fig. 8) of the scratched NiFeCP powder from the electrode is characteristic of the reported MIL-53 diffractogram, and reveals that the as prepared NiFeCP film contains $\mathrm{MOF}$ components, where $\mathrm{Ni}$ atoms and $\mathrm{Fe}$ atoms are randomly arranged in the coordination polymer scaffold encompassed in large square-shaped pores ${ }^{29,32,33}$. However, other amorphous coordination polymer, metal-oxo species could not be excluded by the XRD diffractogram. After electrolysis, the MOFlike characteristic peaks associated with NiFeCP could not be observed in the XRD diffractogram, which may be a result of that excessive terephthalates in the as prepared NiFeCP film introduced by fast electrochemical deposition process can be removed during activation process.

The scanning electron microscopy (SEM) images (Supplementary Fig. 9), demonstrate that as prepared NiFeCP/NF is a $3 \mathrm{D}$ macroscopic film, which is uniformly covered on the surface of the NF skeleton. After the OER test, no obvious morphology change is observed for $\mathrm{NiFeCP/NF}$.

Additionally, high-angle annular dark-field scanning transmission electron microscopy (HAADF-STEM) elemental mapping shows a homogeneous distribution of $\mathrm{Ni}, \mathrm{Fe}, \mathrm{C}$, and $\mathrm{O}$ elements in pristine NiFeCP (Fig. 3a). After being subjected to OER electrochemical experiments, $\mathrm{C}, \mathrm{O}, \mathrm{Ni}$, and $\mathrm{Fe}$ remain uniformly distributed in the post-OER NiFeCP (Fig. 3b). Energydispersive X-ray spectroscopy (EDS) shows that the Fe/Ni atomic ratio in NiFeCP is consistent at 1:9 both before and after OER (Supplementary Fig. 10); however, the component of carbon lost partially, hinting that the partial dissociation of the organic ligands during OER.

X-ray photoelectron spectroscopy (XPS) of C $1 \mathrm{~s}, \mathrm{O} 1 \mathrm{~s}, \mathrm{Fe} 2 \mathrm{p}$, and $\mathrm{Ni} 2 \mathrm{p}$ before and after OER electrochemical experiments are presented in Supplementary Fig. 11a, Fig. 4. As shown in Fig. 4a, the $\mathrm{C} 1 \mathrm{~s}$ signal can be deconvoluted into three surface components, corresponding to the organic ligands at binding energies of $284.8 \mathrm{eV}$ (the $\mathrm{C}-\mathrm{C}$ bonds), $286.0 \mathrm{eV}$ (the $\mathrm{C}-\mathrm{O}$ bonds) and 288.8 $\mathrm{eV}$ (carboxylate $\mathrm{O}=\mathrm{C}-\mathrm{O}$ groups) ${ }^{29,33}$. The $\mathrm{C} 1 \mathrm{~s}$ binding energies are consistent before and after OER. After OER, the signal ascribed to $K$ can be observed on the surface of NiFeCP/NF, which may derive from residual $\mathrm{KOH}$ from the electrolyte. As shown in Fig. 4b, the $\mathrm{O} 1 \mathrm{~s}$ signal can be deconvoluted by fitting different peaks at binding energies of around 529.5, 531.0, 531.6, 532.9 , and $533.4 \mathrm{eV}$, which are attributed to oxygen atoms on metal-oxygen bonds, metal-hydroxyl species, carboxylate group of the organic ligands, and water, respectively ${ }^{32-34}$. The $\mathrm{O} 1 \mathrm{~s}$ binding energies are consistent before and after OER, however the relative intensity of metal-oxygen bonds and metal-hydroxyl species increased after OER. NiFeCP shows peaks at binding energies of $712 \mathrm{eV}$, and $725 \mathrm{eV}$, which are corresponded to $\mathrm{Fe}^{3+}$ $2 \mathrm{p}_{3 / 2}$ and $2 \mathrm{p}_{1 / 2}$, respectively (Fig. $\left.4 \mathrm{c}\right)^{33}$. NiFeCP shows characteristic peaks associated with the $\mathrm{Ni}^{2+}$ oxidation state (Fig. $4 \mathrm{~d}$ ). $\mathrm{Ni}-\mathrm{O}$ species associated with $\mathrm{Ni}$ atoms and the organic ligands are observed at binding energies of $855.5 \mathrm{eV}\left(2 \mathrm{p}_{3 / 2}\right)$ and $873.0 \mathrm{eV}$ 

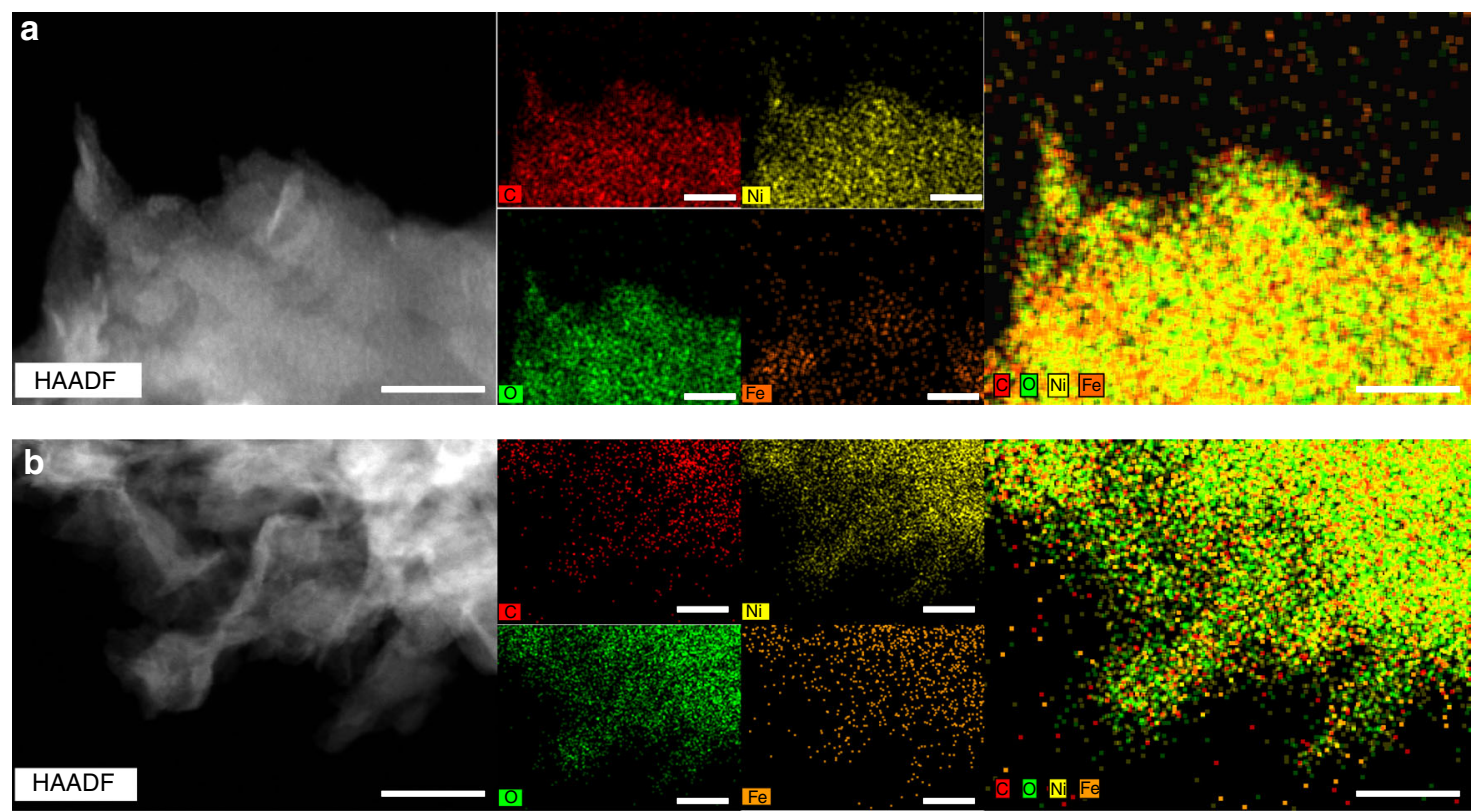

Fig. 3 HAADF-STEM images and corresponding elemental mappings of NiFeCP/NF. Particles detached by sonication from a as prepared NiFeCP/NF electrode and $\mathbf{b}$ the electrode after OER test. The scale bars are $30 \mathrm{~nm}$
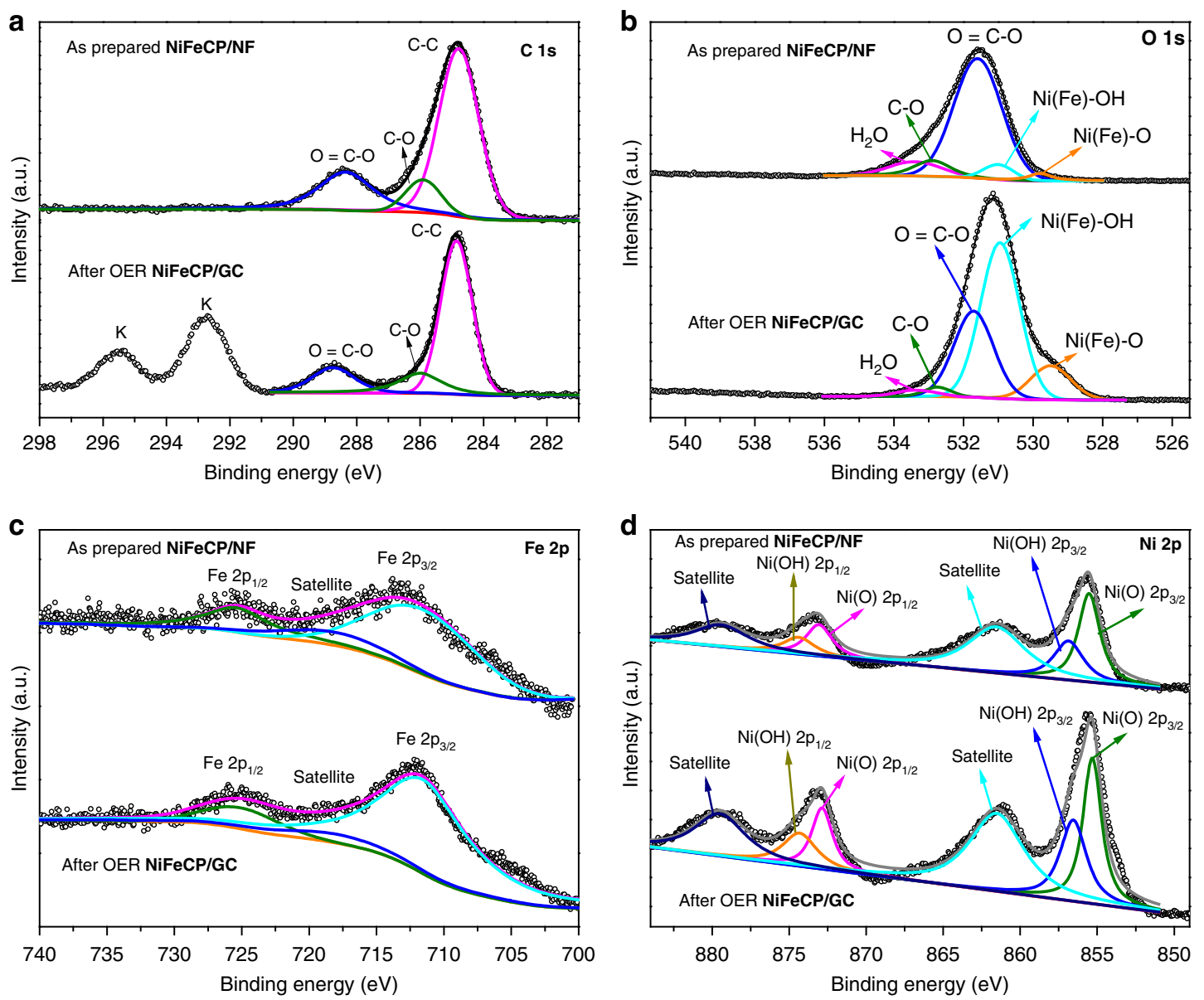

Fig. 4 XPS measurements. High-resolution XPS spectra of a C 1s, b O 1s, c Fe $2 p$, and $\mathbf{d}$ Ni $2 p$ for the NiFeCP/NF electrode before and after OER test 

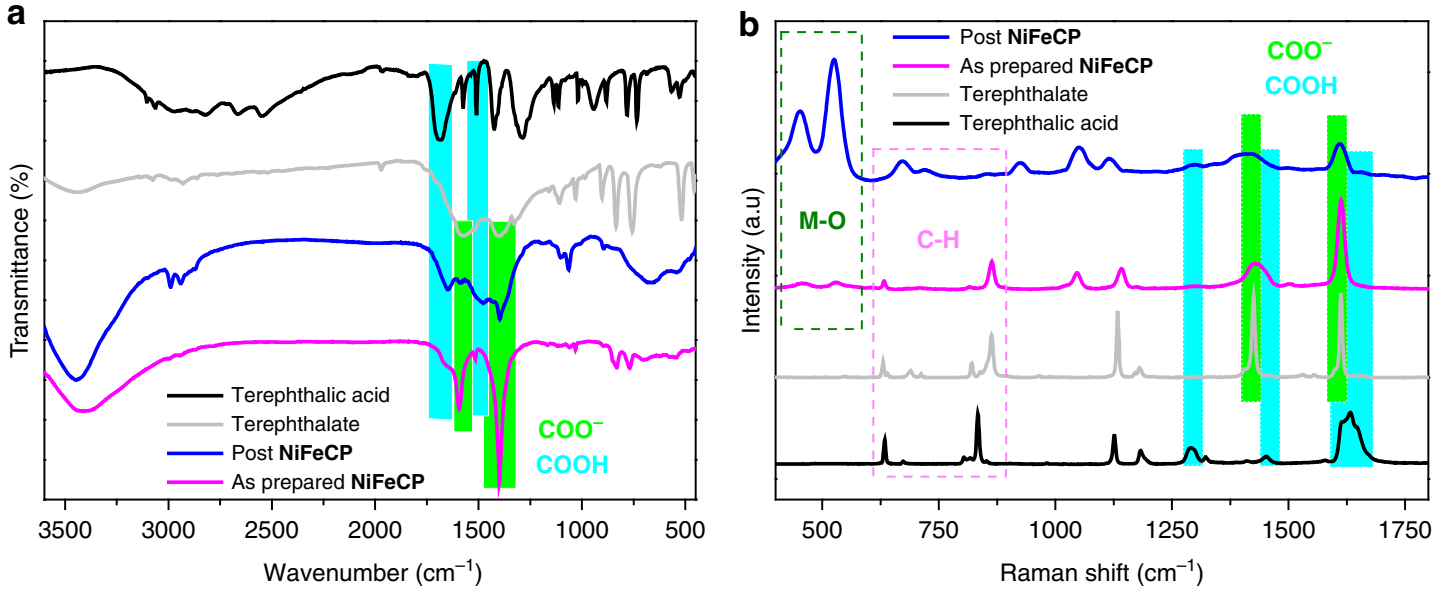

Fig. 5 FT-IR and Micro-Raman measurements. a FT-IR spectra of dried NiFeCP powder scratched from the electrode before and after OER. b Micro-Raman spectra of NiFeCP/NF electrode before and after OER. Terephthalic acid and Na terephthalate as references

$\left(2 \mathrm{p}_{1 / 2}\right)$, while $\mathrm{Ni}-\mathrm{OH}$ species are attributed to the binding energy peaks at $856.9 \mathrm{eV}\left(2 \mathrm{p}_{3 / 2}\right)$ and $874.4 \mathrm{eV}\left(2 \mathrm{p}_{1 / 2}\right)^{32}$. The presence of $\mathrm{Ni}-\mathrm{OH}$ species proves the above-mentioned hypothesis regarding the change of color. The ratio of the integrated area associated with the $\mathrm{Ni}-\mathrm{OH} / \mathrm{NiO}$ peaks increased from 3:5 to 4:5 after electrolysis, and the ratio of metal-oxygen bonds and metal-hydroxyl species increased from $\mathrm{O} 1 \mathrm{~s}$ signal. In order to exclude the influences of $\mathrm{Ni}$ component form $\mathrm{Ni}$ foam, $\mathrm{NiFeCP}$ was also deposited on the surface of glassy carbon substrate (NiFeCP@GC) to study the surface oxidation states by XPS (Supplementary Fig. 11b). Without the influences of $\mathrm{Ni}$ foam, from the Ni 2p signal of high-resolution XPS spectra (Supplementary Fig. 12), the ratio for the relative intensity of metalhydroxyl species and metal-oxygen bonds was found obviously increased after OER. The analysis of XPS spectra of the sample from $\mathbf{N i F e C P / N F}$ and $\mathrm{NiFeCP/GC}$ could give a consistent indication, that the carboxylate groups can partially de-coordinate from the metal centers of as prepared NiFeCP.

The Fourier transform infrared (FT-IR) spectra of powder scratched from as prepared $\mathbf{N i F e C P / N F}$ and the electrode after OER were investigated. As shown in Fig. 5a, two distinct peaks at $1384 \mathrm{~cm}^{-1}$ and $1579 \mathrm{~cm}^{-1}$, corresponding to the symmetric and asymmetric vibrations, respectively, of the carboxylate groups derived from the coordinated terephthalate, can be observed for the samples of as prepared and after OER ${ }^{24}$. Furthermore, two distinct absorption peaks at $1427 \mathrm{~cm}^{-1}$ and $1684 \mathrm{~cm}^{-1}$ are observed before and after OER corresponding to the uncoordinated carboxylate moiety of terephthalate ${ }^{32}$. The ratio of the uncoordinated carboxylate group increased after OER and is considered to have resulted by the de-coordination of the carboxylate groups from the metal centers. It is worth mentioning that for the MOF of MIL-53(FeNi) obtained by hydrothermal synthesis, the distinct absorption peaks of uncoordinated carboxylate can not be observed ${ }^{32}$. The Micro-Raman spectra (Fig. 5b) of NiFeCP/NF electrode exhibits a doublet at $1612 \mathrm{~cm}^{-1}$ and $1429 \mathrm{~cm}^{-1}$ before and after water oxidation, which corresponds to the in- and out- of phase stretching modes of the coordinated carboxylate groups, respectively. These two peaks of stretching modes were broad, which covered the moiety of uncoordinated carboxylate (1631 and $\left.1451 \mathrm{~cm}^{-1}\right)$. Meanwhile, the vibration peak at $1293 \mathrm{~cm}^{-1}\left(A_{g}\right.$ mode) of uncoordinated carboxylates can be obviously observed after OER ${ }^{35}$, indicating the presence of uncoordinated carboxylates groups during OER. The intensity of the metal-O vibration peaks at $460 \mathrm{~cm}^{-1}$ and $530 \mathrm{~cm}^{-1}$ increase after electrolysis as a result of the de- coordination of the carboxylate groups from the metal centers, and the generation of metal hydroxide species.

Combining the information derived from the above characterization suggests that part of the coordinated carboxylate groups can dissociated from $\mathrm{NiFeCP} / \mathrm{NF}$, and in doing so, forming additional free uncoordinated carboxylate sites and additional metal hydroxide sites during OER. Meanwhile, NiFeCP/NF contains metal hydroxide species, coordinated and uncoordinated carboxylate groups both before and after OER.

As the uncoordinated carboxylate group is always present in NiFeCP during water oxidation, we investigated the kinetic function of the uncoordinated carboxylates during water oxidation. As previously reported, increasing the electron density of the metal centers in a water oxidation catalyst may result in changes the Fermi level moving closer to the $\mathrm{O} 2 \mathrm{p}$ states, and concomitantly resulting in a transfer of the concerted proton-electron transfers process (c-PET) to the non-concerted proton-electron transfers(n-PET) process for $\mathrm{OER}^{36}$.

As the carboxylate is a strong electron-donating ligand, it is necessary to determine the type of proton-coupled electron transfer processes for $\mathrm{NiFeCP}$ during water oxidation. Because for a catalyst to proceed via a n-PET pathway, the proton transfer process may not be involved in the rate determining step (RDS), therefore, the influence of the Lewis base will be difficult to be determined ${ }^{37}$.

The study of the $\mathrm{pH}$ dependence on OER activity can provide useful insight on the kinetics and intermediates of the reaction. In this work, $\mathrm{pH}$-dependence studies were performed in strongly basic solutions to probe the intrinsic activity of the catalysts ${ }^{38}$. The RHE scale was used to determine the $\mathrm{pH}$ dependence of the reaction kinetics to avoid the change in thermodynamic driving force at different $\mathrm{pH}$ values. The position of the redox peaks of NiFeCP and NiFe LDH are pH-dependent (Fig. 6a, b), as shown in Supplementary Fig. 13, the NiFeCP and NiFe LDH yielded linear plots of $E_{\text {redox }}(\mathrm{NHE})$ versus $\mathrm{pH}$ with slopes of -88 and $-95 \mathrm{mV}$ per $\mathrm{pH}$, respectively. These values were nearly 1.5 times the theoretical value of $-59 \mathrm{mV}$ per $\mathrm{pH}$ for the $1 \mathrm{H}^{+} / 1 \mathrm{e}^{-}$oxidation of $\mathrm{Ni}^{2+}(\mathrm{OH})_{2}$ to $\mathrm{Ni}^{3+} \mathrm{O}(\mathrm{OH})$; thus, a $3 \mathrm{H}^{+} / 2 \mathrm{e}^{-}$coupled redox process was suggested for both $\mathrm{NiFeCP}$ and NiFe LDH ${ }^{39-41}$. The obtained slopes were in agreement with the previous report, whereby an Fe dopant could strongly decrease the valence state of the $\mathrm{Ni}$ in nickel hydroxide species ${ }^{39,41}$. For catalysts that proceed via a c-PET pathway, the reaction order of $\mathrm{pH}$ would be zero (see Supplementary Note 1 for the details), as the proton is never decoupled from the electron transfer in this 

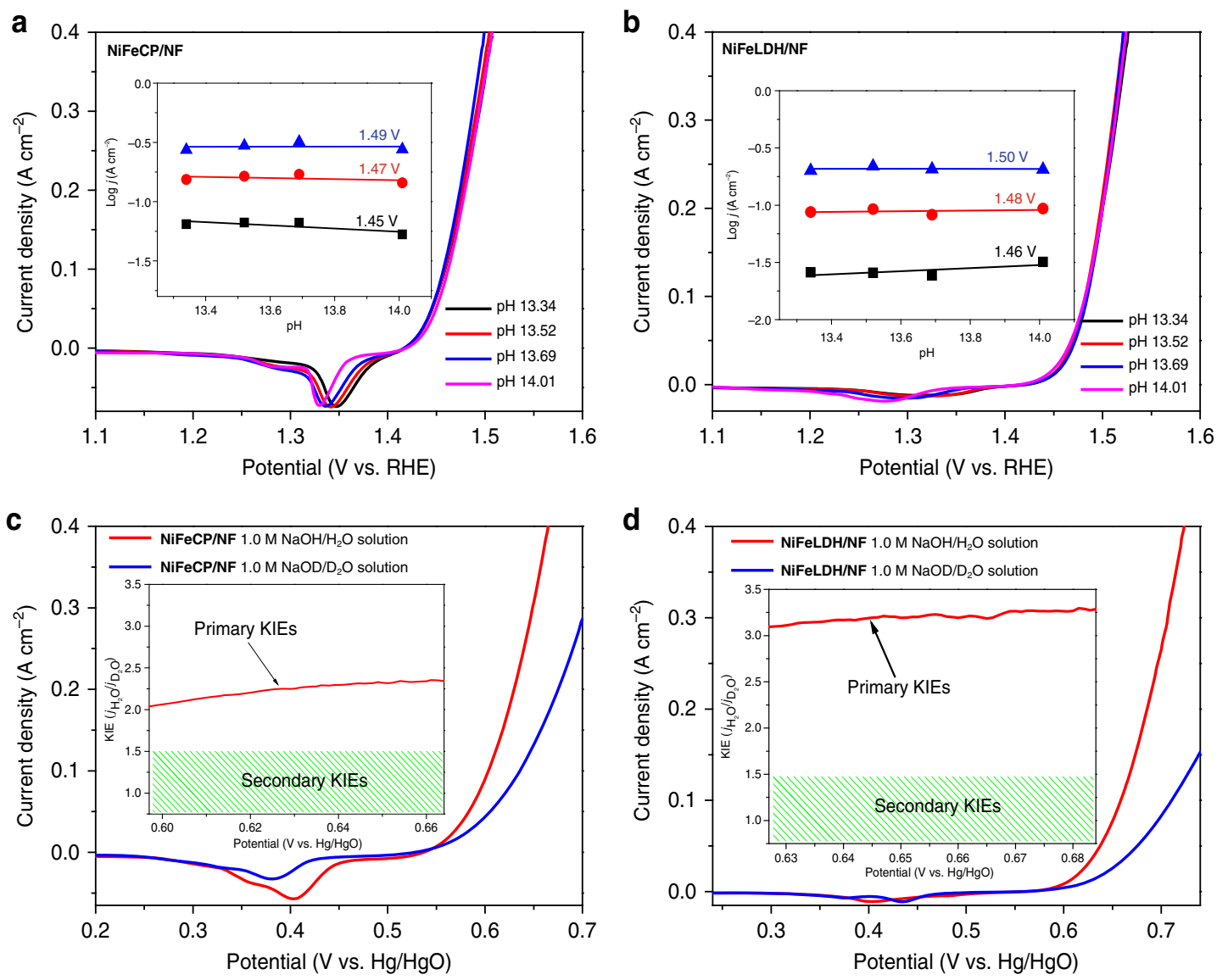

Fig. $\mathbf{6 H}$ dependence and kinetic isotope effects studies. LSV curves of a NiFeCP/NF and $\mathbf{b}$ NiFe LDH/NF in KOH solutions as a function of pH. The inset exhibits the reaction order of $\mathrm{pH}$ value. LSV curves of: $\mathbf{c}$ NiFeCP/NF and $\mathbf{d} \mathbf{~ N i F e ~} \mathbf{L D H} / \mathbf{N F}$ in aqueous $1.0 \mathrm{M} \mathrm{NaOH}$ solutions and $1.0 \mathrm{M}$ NaOD $\mathrm{D}_{2} \mathrm{O}$ solutions. The insets are the kinetic isotope effect values vs potential

case $^{36,38,42}$. Both NiFeCP and NiFe LDH exhibit negligible $\mathrm{pH}$ dependent OER kinetics (Fig. 6a, b), which indicates that both $\mathrm{NiFeCP}$ and $\mathrm{NiFe}$ LDH proceed via a c-PET process as the RDS during the water oxidation reaction, and naturally, the proton transfer must be involved ${ }^{38}$.

Deuterium kinetic isotope effects (KIEs) can reflect the proton transfer kinetic information of water oxidation reactions, and therefore, help to interpret the RDS of the catalytic processes ${ }^{43-45}$. The presence of KIEs (KIEs $>1.5$ ) is considered as evidence that proton transfer is involved in the RDS (or, at least, in one of the steps affecting the reaction rate $)^{46}$. The KIEs experiments in 1.0 M NaOD $\mathrm{D}_{2} \mathrm{O}$ solution were performed to obtain insight into the role of proton transfer during the catalytic RDS. The acidity difference between $\mathrm{D}_{2} \mathrm{O}$ and $\mathrm{H}_{2} \mathrm{O}$ caused by different dissociation constants was eliminated by the overpotential correction (see Supplementary Note 2 for an explanation). As the Faradaic Efficiency for both $\mathrm{NiFeCP} / \mathrm{NF}$ and NiFe LDH/NF electrodes are close to $100 \%$ in aqueous and deuterated electrolytes (Supplementary Fig. 14), the accumulated charge for NiFeCP/NF and NiFe LDH/NF electrodes can be almost quantitatively consumed for OER, the corresponding current can be used directly for the calculation of KIEs. The LSV curve of NiFeCP/NF in a $1.0 \mathrm{M}$ $\mathrm{NaOD} \mathrm{D}_{2} \mathrm{O}$ solution exhibits significantly lower current density in comparison with that of $\mathrm{NiFeCP/NF}$ in the $1.0 \mathrm{M} \mathrm{NaOH} \mathrm{H} \mathrm{H}_{2} \mathrm{O}$ solution by a factor about 2.2 over the entire potential range (Fig. 6c). The KIEs value of NiFeCP/NF indicates that the RDS for water oxidation involves cleavage of the $\mathrm{O}-\mathrm{H}$ bonds. For the comparative sample, the NiFe LDH/NF shows a larger primary isotope effects (Fig. 6d). The $\mathrm{pH}$-dependence and KIE studies confirmed that the cleavage of the $\mathrm{O}-\mathrm{H}$ bonds are involved for both $\mathbf{N i F e C P / N F}$ and NiFe LDH/NF. The proton vibrational wave function overlap plays an important role in determining the reaction rates and KIEs of c-PET reactions. Moreover, this overlap depends strongly on the proton donor-acceptor distance: the overlap is larger for shorter distances. Accordingly, the reaction rate increases and KIEs often decreases as the proton donor-acceptor distance decreases ${ }^{47-49}$. As both NiFeCP/NF and NiFe LDH/NF catalyze water oxidation by metal-oxo species with c-PET pathway, the smaller value of KIEs for NiFeCP than that of NiFe LDH suggests that there are functional groups nearby the catalytic centers to promote the kinetics of water oxidation. Further, anhydrous disodium terephthalate $(0.3 \mathrm{M}$, almost saturated) was added into the electrolytes, the catalytic current of NiFe LDH slightly raised ( 1.1 times) in $1.0 \mathrm{M} \mathrm{NaOH}$ $\mathrm{H}_{2} \mathrm{O}$ solution (Supplementary Fig. 15a), obviously increased $(\sim 1.3$ times) in $1.0 \mathrm{M} \mathrm{NaOD} \mathrm{D}_{2} \mathrm{O}$ solution (Supplementary Fig. 15b), resulting in the KIEs decreased from $\sim 3.1$ to 2.3 with the presence of terephthalate for the carboxylate free catalyst NiFe LDH (Supplementary Fig. 15c, d). When concentration of terephthalate in electrolytes is high, the carboxylates of terephthalate will have opportunity to help handling the proton transfer at the surface of NiFe LDH, for which, the carboxylates will serve the similar function as in the NiFeCP material, resulting in a smaller KIEs. This control experiment strongly proves the proton transfer relay promotion of the secondary coordination sphere effects caused by the uncoordinated carboxylates in NiFeCP.

To provide further support for the existence of proton transfer relays in NiFeCP for OER, electrochemical proton inventory 

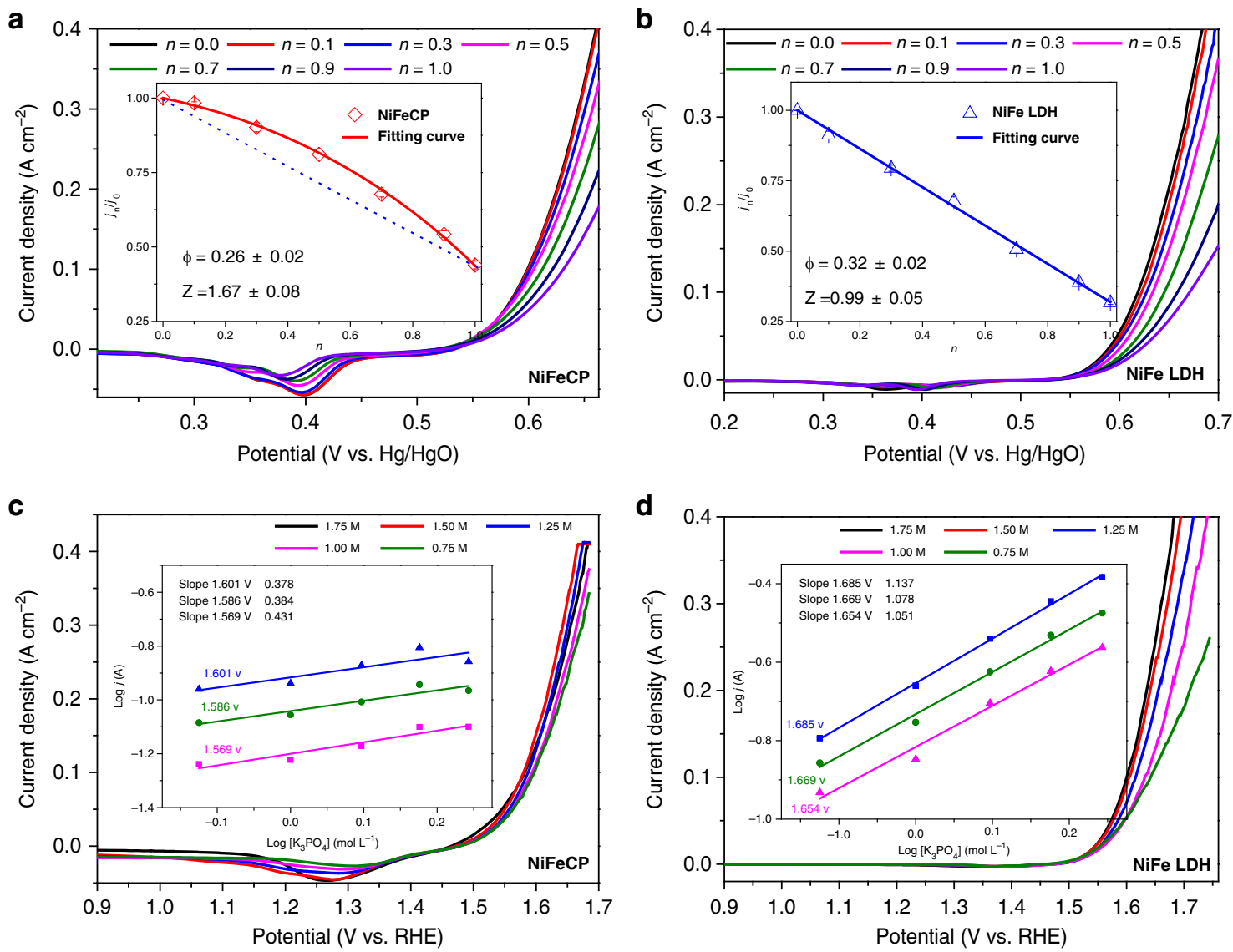

Fig. 7 Proton inventory and atom proton transfer studies. LSV curves of $\mathbf{a} \mathbf{~ N i F e C P / N F}$ and $\mathbf{b}$ NiFe $\mathbf{L D H} / \mathbf{N F}$ in mixed solutions of $1.0 \mathrm{M} \mathrm{NaOH}$ in $\mathrm{H}_{2} \mathrm{O}$ and 1.0 M NaOD in $\mathrm{D}_{2} \mathrm{O}$ with different ratios as a function of atom fractions of deuterium $(n)$. The insets exhibit the plots of $j_{n} / j_{0}$ as a function of $n$, where $n=$ $[\mathrm{D}] /([\mathrm{D}]+[\mathrm{H}])$ and at a certain potential were abbreviated as $j_{n} j_{\mathrm{O}}=j_{\mathrm{H} 2 \mathrm{O}}$ (all reported values are averages from 12 different potentials, which can be find in Supplementary Note 3, all errors are given as standard deviations). LSV curves of: c NiFeCP/NF and $\mathbf{d}$ NiFe LDH/NF as a function concentration of $\mathrm{K}_{3} \mathrm{PO}_{4}$ at $\mathrm{pH}=12.65$, the insets exhibit the reaction order of $\left[\mathrm{K}_{3} \mathrm{PO}_{4}\right]$

studies were conducted. The proton inventory method is particularly useful for resolving the number of exchangeable hydrogenic sites that contribute to the catalytic rate ${ }^{50-54}$. The key parameter of proton inventory studies, isotope fractionation factor $(\phi)$ is related to the propensity for a hydrogenic site in the RDS of the reaction to interact with $\mathrm{D}^{+}$compared to water, which only depends on the chemical structure in the immediate neighborhood of the isotopic site, and for a given functional group bearing exchangeable hydrogen will tend to have the same fractionation factors ${ }^{53}$. The dependence of the reaction rate attenuation on the atom fractions of deuterium in the electrolyte was measured (see Supplementary Note 3 for the details), and the data was fitted by a modified Kresge-Gross-Butler equation (Supplementary eqn. 8$)^{50-52}$, where $\phi$ is the isotopic fractionation factor and $Z$ is the $Z$-effect related to the aggregate isotope effect from multiple equivalent hydrogenic sites, called $Z$-sites, with individual weak isotope effects ${ }^{52,53}$. In a plot of $j_{n} / j_{0}$ as a function of $n$, the shape of the resulting curve is dependent on the relative sizes of $\phi$ and $Z$. When $Z>1$ suggests there is an aggregate inverse isotope effect at the $Z$-sites contributing to the observed kinetics, and $Z \approx 1$ suggests there are no $Z$-sites contributing to the observed kinetics ${ }^{51,52}$. For NiFeCP/NF electrode (Fig. 7a), a nonlinear dome-shaped response with a $\phi$ of 0.26 and a $Z$ of 1.6 can be observed. The large $Z$-effect indicated that the RDS of water oxidation at the active sites of $\mathrm{NiFeCP}$ coupled with an aggregate inverse-isotope effect from the $Z$-sites (uncoordinated carboxylate $)^{50-52}$. However, as shown in Fig. $7 \mathrm{~b}$, the plot of $j_{n} / j_{0}$ as a function of $n$ for the carboxylate-free NiFe LDH/NF electrode, results in a linear attenuation with $Z \approx 1$ and $\phi \approx 0.32$, which suggested that only one hydrogenic site (water) is involved in the RDS of the catalytic processes, and no proton relays contribute to the observed kinetics ${ }^{52,55}$. The smaller value of $\phi$ for NiFeCP indicated the uncoordinated carboxylate provided extra hydrogenic site, which influenced the transition-state hydrogen bridges corresponding to proton transfer in the RDS of OER, otherwise, a similar value of $\phi$ as NiFe LDH should be obtained ${ }^{52,53}$. Proton inventory studies strongly support the results obtained by KIEs measurements where the proton delivery from catalytic centers of $\mathrm{NiFeCP}$ to electrolyte received the assistance of uncoordinated carboxylates.

When the water oxidation RDS of a catalyst is related to the proton transfer, the atom proton transfer (APT), with a Lewis base in solution as a proton acceptor, can decrease the barrier of the reaction. Hence, Lewis bases (such as phosphate) in solution usually influence the reaction kinetics ${ }^{56-58}$. The relationship between catalytic activity and the concentration of additional base $\left(\mathrm{K}_{3} \mathrm{PO}_{4}\right)$ were therefore studied. When an electrode undergoes a extra base-dependent pathway for water oxidation, because of the linear relationship between the water oxidation reaction rate $k_{\mathrm{cat}}$ and catalytic current density, it should be first order reactions for the concentration of phosphate ( $\left.\rho_{\text {phosphate }}\right)$ (see Supplementary Note 4 for an explanation $)^{59,60}$. The first order reactions of phosphate have been widely observed in catalyst-modified electrodes for OER, when the RDS for water oxidation is clearly related to proton transfer ${ }^{56,61}$. As shown in Fig. $7 \mathrm{~d}$, the $\rho_{\text {phosphate }}$ for $\mathbf{N i F e} \mathbf{L D H} / \mathrm{NF}$ is around 1 over the entire obvious catalytic 

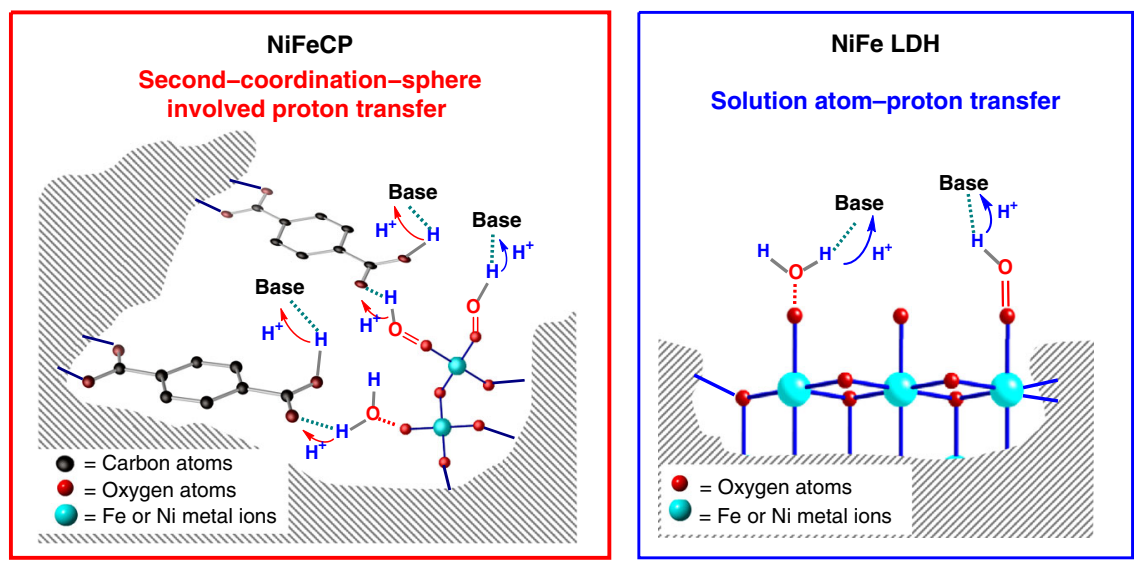

Fig. 8 Schematic illustration of the proposed proton transfer processes: second-coordination-sphere involved proton transfer for NiFeCP (left) and APT for NiFe LDH (right)

potential range, indicating that solution APT can occur for the carboxylate-free NiFe LDH/NF. However, although the NiFeCP/ NF is a catalyst that involves proton transfer event in the RDS, the $\rho_{\text {phosphate }}$ associated with $\mathrm{NiFeCP} / \mathrm{NF}$ is significantly less than one (approximately 0.38 ) over the entire obvious catalytic potential range (Fig. 7c), which suggests the solution APT process attributed from the extra base is greatly suppressed. The solution APT process is a diffusion controlled event, and therefore, is influenced by the concentration of base, however, for NiFeCP/ NF, the uncoordinated carboxylate groups are located in the vicinity of the catalytic center, and thus, fast proton exchange should preferentially occur, and thereafter, the external base from electrolyte can deprotonate the carboxylic acid produced from second-coordination-sphere involved proton transfer processes. Experimental results of NiFeCP catalyst have shown the smaller value of KIEs, non-linear response to the atom fraction of deuterium, and an effective suppression of solution APT in contrast to the carboxylate-free NiFe LDH catalyst, indicating that the uncoordinated carboxylate groups in $\mathrm{NiFeCP}$ provide internal bases, as shown in Fig. 8, which serve as a proton transfer relays.

\section{Discussion}

The phosphate can serve to neutralize the protons generated by the c-PET electrode reaction and to convert, at least partially, proton diffusion toward the solution into a protonated phosphate diffusion toward the solution, and concomitantly, a diffusion of phosphate toward the electrode. Additionally, the phosphate can participate as a reactant to the c-PET electrode reaction ${ }^{62}$. Under buffer-free conditions, e.g., a $1.0 \mathrm{M} \mathrm{KOH}$ solution, APT-type catalysts have no buffer anion to assist proton transfer. However, for the catalysts, in which second-coordination-sphere is involved in proton transfer process, the internal base itself will provide the functions of a buffer anion to handle the proton, which can optimize the proton transfer during the reaction, and therefore increase reaction rate of water oxidation.

This second-coordination-sphere involved proton transfer pathway is certainly playing a key role during water oxidation in the OEC of PSII, as previously mentioned. The observation of the proton transfer relay phenomenon by uncoordinated carboxylate groups in the synthetic NiFeCP catalyst suggests that the secondcoordination-sphere can be synthetically constructed in a heterogeneous artificial water oxidation catalyst, which is an interesting discovery. This may explain why NiFeCP and NiFe LDH are both water oxidation catalysts but proceed via different proton transfer pathways, and why the activity in terms of onset potential, overpotential and Tafel slope for $\mathbf{N i F e C P / N F}$ are superior to those of NiFe LDH/NF. Certainly, further studies on second-coordination-sphere involving proton-coupled electron transfer catalysts are required to design and synthesis of more advanced heterogeneous water oxidation catalysts.

Inspired by the second-coordination-sphere of water oxidation catalyst in PSII, a coordination polymer containing Ni/Fe cations and terephthalate was electrochemically deposited in situ on a nickel foam as the functional electrode (NiFeCP/NF) for water oxidation. Various characterization techniques demonstrated that both coordinated and uncoordinated carboxylate groups in the film were maintained after electrolysis. NiFeCP/NF exhibits outstanding electrocatalytic water oxidation activity with a low overpotential of $188 \mathrm{mV}$ at $10 \mathrm{~mA} \mathrm{~cm}^{-2}$ in $1.0 \mathrm{M} \mathrm{KOH}$, and a small Tafel slope of $29 \mathrm{mV} \mathrm{dec}^{-1}$. To the best of our knowledge, the as-fabricated $\mathbf{N i F e C P / N F}$ electrode is one of the promising material catalysts for oxygen evolution. Comprehensive mechanism studies on NiFeCP and the benchmark OER catalyst of NiFe LDH were performed. NiFeCP and NiFe LDH exhibit $\mathrm{pH}$-independent OER activities on the RHE scale, suggesting concerted proton-coupled electron transfer (c-PET) plays a great role in catalyzing the OER for both catalysts. Deuterium kinetic isotope effect measurements show a smaller value of KIEs for NiFeCP than that of carboxylate-free NiFe LDH; proton inventory studies show a non-linear dependence on deuterium concentration for NiFeCP; and APT measurements show a smaller external base impact from the electrolyte on NiFeCP than that of NiFe LDH. All experimental results suggest that the uncoordinated carboxylates can serve as proton transfer relays nearby the catalytic centers of NiFeCP. Such proton transfer relays can significantly improve the activity of the catalyst undergoing cPET pathway for OER. This interesting discovery may provide a new perspective on the design and synthesis of more advanced heterogeneous catalysts for further enhancing catalytic activity through second-coordination-sphere engineering, and to form a base for next level research in the field of OER.

\section{Methods}

Preparation of NiFeCP/NF electrodes. As a typical procedure, the electrochemical-deposition was carried out in a three-electrode electrochemical cell using a $1 \times 2 \mathrm{~cm}^{2}$ nickel foam as the working electrode, a platinum mesh $(1 \times$ $1.5 \mathrm{~cm}^{2}$ ) as the counter electrode and a $\mathrm{Hg} / \mathrm{HgO}$ as the reference electrode. Before electrodeposition, the nickel foam was cleaned in a $\mathrm{HCl}$ solution $(1.0 \mathrm{M})$, rinsed with water and ethanol, then dried by $\mathrm{N}_{2}$ flow. Preliminary electrocatalytic performances of NiFeCP/NF electrodes prepared by different $\mathrm{Fe} / \mathrm{Ni}$ ratio in electrolyte were characterized, when $\mathrm{Fe} / \mathrm{Ni}$ ratio equaled to $3 / 7$ the $\mathrm{NiFeCP} / \mathrm{NF}$ electrode displayed the best catalytic activity with the lowest overpotential about $180 \mathrm{mV}$ for $10 \mathrm{~mA} \mathrm{~cm}^{-2}$ and lowest Tafel slope of $29 \mathrm{mV} \mathrm{dec}^{-1}$ for OER. In details, the electrochemical-deposition solution contained $0.6 \mathrm{mmol}$ Terephthalic acid, $0.7 \mathrm{mmol} \mathrm{Ni}\left(\mathrm{NO}_{3}\right)_{2} \cdot 6 \mathrm{H}_{2} \mathrm{O}, 0.3 \mathrm{mmol} \mathrm{Fe}\left(\mathrm{NO}_{3}\right)_{3} \cdot 9 \mathrm{H}_{2} \mathrm{O}, 0.6 \mathrm{ml}$ water and $10 \mathrm{ml} \mathrm{DMF}$ 
The NiFeCP films were prepared through a repeated double-current pulse chronopotentiometry (r-DCPC) method that involved two current pulses at $-3.0 \mathrm{~mA}$ $\mathrm{cm}^{-2}$ and $0 \mathrm{~mA} \mathrm{~cm}^{-2}$ for $5 \mathrm{~s}$ and $10 \mathrm{~s}$, respectively, as one DCPC deposition cycle. During this electro-deposition process, $\mathrm{OH}^{-}$was generated by the reduction of nitrate and water. With the increasing of the $\mathrm{pH}$ value nearby the working electrode, terephthalate acid can be deprotonated, and thereafter, react with metal cations forming a coordination polymer. High quality NiFeCP films can be obtained by repeating DCPC deposition after 600 cycles. After deposition, the NiFeCP/NF electrode was carefully withdrawn from the electrolyte, rinsed with DMF and ethanol, and then dried in air. Before water oxidation measurements, the as prepared $\mathrm{NiFeCP} / \mathrm{NF}$ electrodes were activated at $50 \mathrm{~mA} \mathrm{~cm}^{-2}$ current density in $1.0 \mathrm{M} \mathrm{KOH}$ for $10 \mathrm{~min}$ to remove the excessive the terephthalates in NiFeCP introduced by the fast electrochemical deposition process. The activated $\mathrm{NiFeCP} /$ NF electrodes were rinsed with water, dried in air, and then measured the water oxidation activities in fresh electrolytes.

Electrochemical Measurements. Linear sweep voltammetry (LSV) measurements were carried out on a CHI 660e potentiostat. All the electrochemical characterizations were carried out at the temperature of $298 \mathrm{~K}$, which was controlled by thermostatic water-bath. OER were studied in a standard three-electrode glass cell connected to $\mathrm{CHI} 660 \mathrm{e}$ workstation using the prepared materials as the working electrode, a Pt mesh as the counter electrode and a $\mathrm{Hg} / \mathrm{HgO}$ electrode as the reference electrode. All the measured potentials were converted to reversible hydrogen electrodes (RHE) according to $E_{R H E}=E_{H g / H g O}+0.059 \mathrm{pH}+0.0977 \mathrm{~V}$. The LSV measurements were performed at a scan rate of $5 \mathrm{mV} \mathrm{s}^{-1}$ to evaluate the catalytic activities of the electrode films. All the polarization measurements were iR compensated (80\%) unless otherwise stated. Chronopotentiometry measurements were recorded under the same experimental setup without iR correction.

Determination of normalized LSV curves. Electrochemically active surface area (ECSA) of electrode was obtained from cyclic voltammetry (CV) curves, In details, by plotting the $\Delta j\left(\left|j_{\text {charge }}-j_{\text {discharge }}\right|\right)$ at Faradaic silence potential range against the scan rates, the linear slope can be obtained, which is a positive correlation with the double-layer capacitance $\left(\mathrm{C}_{\mathrm{dl}}\right)$, and been used to represent the corresponding ECSA.

Determination of Faradaic Efficiency. The faradaic efficiency was performed in a gastight electrochemical-cell using a Pt mesh as the counter electrode, NiFeCP/NF or NiFe LDH/NF as the working electrode and a $\mathrm{Hg} / \mathrm{HgO}$ electrode as the reference electrode, respectively. $1.0 \mathrm{M} \mathrm{KOH}$ aqueous solution (or $1.0 \mathrm{M} \mathrm{NaOD} / \mathrm{D}_{2} \mathrm{O}$ solution) was used as electrolyte. Before the measurements, the electrolyte was purged with nitrogen gas for $30 \mathrm{~min}$ to completely remove the oxygen gas in the system. Then, the experiment was performed under the current density of $10 \mathrm{~mA} \mathrm{~cm}^{-2} .0 .5 \mathrm{~mL}$ of gas was analyzed by gas chromatography (GC, Techcomp GC 7890T, Ar carrier gas) after each 9.0 C of charge passed through the electrode.

\section{Data availability}

Data underlying Figs. 2, 6 and 7. Supplementary Figs. 2-5 and 15 are provided as a Source Data file. All other data are available from the corresponding author upon reasonable request.

Received: 8 May 2019; Accepted: 17 October 2019;

Published online: 07 November 2019

\section{References}

1. Kanan, M. W., Surendranath, Y. \& Nocera, D. G. Cobalt-phosphate oxygenevolving compound. Chem. Soc. Rev. 38, 109-114 (2009).

2. Coridan, R. H. et al. Methods for comparing the performance of energyconversion systems for use in solar fuels and solar electricity generation. Energy Environ. Sci. 8, 2886-2901 (2015).

3. Lee, Y., Suntivich, J., May, K. J., Perry, E. E. \& Shao-Horn, Y. Synthesis and activities of rutile $\mathrm{IrO}_{2}$ and $\mathrm{RuO}_{2}$ nanoparticles for oxygen evolution in acid and alkaline solutions. J. Phys. Chem. Lett. 3, 399-404 (2012).

4. Hammes-Schiffer, S. \& Stuchebrukhov, A. A. Theory of coupled electron and proton transfer reactions. Chem. Rev. 110, 6939-6960 (2010).

5. Zhang, M.-T., Irebo, T., Johansson, O. \& Hammarström, L. Proton-coupled electron transfer from tyrosine: a strong rate dependence on intramolecular proton transfer distance. J. Am. Chem. Soc. 133, 13224-13227 (2011).

6. Meyer, T. J., Huynh, M. H. V. \& Thorp, H. H. The possible role of protoncoupled electron transfer (PCET) in water oxidation by photosystem II. Angew. Chem. Int. Ed. 46, 5284-5304 (2007).

7. Duan, L., Wang, L., Li, F., Li, F. \& Sun, L. Highly efficient bioinspired molecular Ru water oxidation catalysts with negatively charged backbone ligands. Acc. Chem. Res. 48, 2084-2096 (2015).
8. Umena, Y., Kawakami, K., Shen, J.-R. \& Kamiya, N. Crystal structure of oxygen-evolving photosystem II at a resolution of 1.9 A. Nature 473, 55 (2011).

9. Kamiya, N. \& Shen, J.-R. Crystal structure of oxygen-evolving photosystem II from Thermosynechococcus vulcanus at 3.7-Å resolution. Proc. Natl Acad. Sci. USA 100, 98 (2003).

10. Kärkäs, M. D., Verho, O., Johnston, E. V. \& Åkermark, B. Artificial photosynthesis: molecular systems for catalytic water oxidation. Chem. Rev. 114, 11863-12001 (2014).

11. Debus, R. J., Strickler, M. A., Walker, L. M. \& Hillier, W. No evidence from FTIR difference spectroscopy that aspartate-170 of the D1 polypeptide ligates a manganese ion that undergoes oxidation during the S0 to S1, S1 to S2, or S2 to S3 transitions in photosystem II. Biochemistry 44, 1367-1374 (2005).

12. Liu, F. et al. Mechanisms of water oxidation from the blue dimer to photosystem II. Inorg. Chem. 47, 1727-1752 (2008).

13. Chen, H., Dismukes, G. C. \& Case, D. A. Resolving ambiguous protonation and oxidation states in the oxygen evolving complex of photosystem II. J. Phys. Chem. B 122, 8654-8664 (2018).

14. Siegbahn, P. E. M. A structure-consistent mechanism for dioxygen formation in photosystem II. Chem. Eur. J. 14, 8290-8302 (2008).

15. Suga, $\mathrm{M}$. et al. Light-induced structural changes and the site of $\mathrm{O}=\mathrm{O}$ bond formation in PSII caught by XFEL. Nature 543, 131 (2017).

16. Zong, R. \& Thummel, R. P. A new family of Ru complexes for water oxidation. J. Am. Chem. Soc. 127, 12802-12803 (2005).

17. Dogutan, D. K., McGuire, R. Jr. \& Nocera, D. G. Electocatalytic water oxidation by cobalt(III) hangman beta-octafluoro corroles. J. Am. Chem. Soc. 133, 9178-9180 (2011).

18. Zeng, Q., Lewis, F. W., Harwood, L. M. \& Hartl, F. Role of ligands in catalytic water oxidation by mononuclear ruthenium complexes. Coord. Chem. Rev. 304-305, 88-101 (2015).

19. Trotochaud, L., Young, S. L., Ranney, J. K. \& Boettcher, S. W. Nickel-iron oxyhydroxide oxygen-evolution electrocatalysts: the role of intentional and incidental iron incorporation. J. Am. Chem. Soc. 136, 6744-6753 (2014).

20. Friebel, D. et al. Identification of highly active $\mathrm{Fe}$ sites in $(\mathrm{Ni}, \mathrm{Fe}) \mathrm{OOH}$ for electrocatalytic water splitting. J. Am. Chem. Soc. 137, 1305-1313 (2015).

21. $\mathrm{Lu}, \mathrm{Z}$. et al. Three-dimensional NiFe layered double hydroxide film for highefficiency oxygen evolution reaction. Chem. Commun. 50, 6479-6482 (2014).

22. Lu, X. \& Zhao, C. Electrodeposition of hierarchically structured threedimensional nickel-iron electrodes for efficient oxygen evolution at high current densities. Nat. Commun. 6, 6616 (2015).

23. Li, Z. et al. Fast electrosynthesis of Fe-containing layered double hydroxide arrays toward highly efficient electrocatalytic oxidation reactions. Chem. Sci. 6 , 6624-6631 (2015).

24. Jiang, J., Huang, L., Liu, X. \& Ai, L. Bioinspired cobalt-citrate metal-organic framework as an efficient electrocatalyst for water oxidation. ACS Appl. Mater. Interfaces 9, 7193-7201 (2017).

25. Wu, H. B. \& Lou, X. W. Metal-organic frameworks and their derived materials for electrochemical energy storage and conversion: promises and challenges. Sci. Adv. 3, eaap9252 (2017).

26. Lu, X.-F. et al. An alkaline-stable, metal hydroxide mimicking metal-organic framework for efficient electrocatalytic oxygen evolution. J. Am. Chem. Soc. 138, 8336-8339 (2016).

27. Dou, S. et al. Atomic-scale $\mathrm{CoO}_{\mathrm{x}}$ species in metal-organic frameworks for oxygen evolution reaction. Adv. Funct. Mater. 27, 1702546 (2017).

28. Shen, J.-Q. et al. Modular and stepwise synthesis of a hybrid metal-organic framework for efficient electrocatalytic oxygen evolution. J. Am. Chem. Soc. 139, 1778-1781 (2017).

29. Hai, G. et al. High-performance oxygen evolution catalyst using twodimensional ultrathin metal-organic frameworks nanosheets. Nano Energy $\mathbf{4 4}$ 345-352 (2018).

30. Wei, Z. et al. Conductive leaflike cobalt metal-organic framework nanoarray on carbon cloth as a flexible and versatile anode toward both electrocatalytic glucose and water oxidation. Inorg. Chem. 57, 8422-8428 (2018).

31. Zhao, S. et al. Ultrathin metal-organic framework nanosheets for electrocatalytic oxygen evolution. Nat. Energy 1, 16184 (2016).

32. Sun, F. et al. NiFe-based metal-organic framework nanosheets directly supported on nickel foam acting as robust electrodes for electrochemical oxygen evolution reaction. Adv. Energy Mater. 8, 1800584 (2018).

33. Li, J., et al. Low-crystalline bimetallic metal-organic framework electrocatalysts with rich active sites for oxygen evolution. ACS Energy Lett. 4 , 285-292 (2018).

34. Xing, J. et al. In situ growth of well-ordered NiFe-MOF-74 on Ni foam by $\mathrm{Fe} 2$ + induction as an efficient and stable electrocatalyst for water oxidation. Chem. Commun. 54, 7046-7049 (2018).

35. Lee, M. W., Kim, M. S. \& Kim, K. Infrared and Raman spectroscopic study of terephthalic acid adsorbed on silver surfaces. J. Mol. Struct. 415, 93-100 (1997).

36. Grimaud, A. et al. Activating lattice oxygen redox reactions in metal oxides to catalyse oxygen evolution. Nat. Chem. 9, 457 (2017). 
37. Costentin, C., Robert, M. \& Savéant, J.-M. Concerted proton-electron transfer reactions in water. Are the driving force and rate constant depending on $\mathrm{pH}$ when water acts as proton donor or acceptor? J. Am. Chem. Soc. 129, 5870-5879 (2007).

38. Giordano, L. et al. $\mathrm{pH}$ dependence of OER activity of oxides: current and future perspectives. Catal. Today 262, 2-10 (2016).

39. Louie, M. W. \& Bell, A. T. An investigation of thin-film Ni-Fe oxide catalysts for the electrochemical evolution of oxygen. J. Am. Chem. Soc. 135, 12329-12337 (2013).

40. Dincă, M., Surendranath, Y. \& Nocera, D. G. Nickel-borate oxygen-evolving catalyst that functions under benign conditions. Proc. Natl Acad. Sci. USA 107, 10337 (2010).

41. Zhang, W., Wu, Y., Qi, J., Chen, M. \& Cao, R. A thin NiFe hydroxide film formed by stepwise electrodeposition strategy with significantly improved catalytic water oxidation efficiency. Adv. Energy Mater. 7, 1602547 (2017).

42. Koper, M. T. M. Theory of multiple proton-electron transfer reactions and its implications for electrocatalysis. Chem. Sci. 4, 2710-2723 (2013).

43. Moonshiram, D., Purohit, V., Concepcion, J., Meyer, T. \& Pushkar, Y. Mechanism of catalytic water oxidation by the ruthenium blue dimer catalyst: comparative study in $\mathrm{D}_{2} \mathrm{O}$ versus $\mathrm{H}_{2} \mathrm{O}$. Mater 6, 392-409 (2013).

44. Yamada, H., Siems, W. F., Koike, T. \& Hurst, J. K. Mechanisms of water oxidation catalyzed by the cis,cis-[(bpy) $2 \mathrm{Ru}(\mathrm{OH} 2)] 2 \mathrm{O} 4+$ Ion. J. Am. Chem. Soc. 126, 9786-9795 (2004).

45. Chen, Z. et al. Concerted $\mathrm{O}$ atom-proton transfer in the $\mathrm{O}-\mathrm{O}$ bond forming step in water oxidation. Proc. Natl Acad. Sci. USA 107, 7225 (2010).

46. Krishtalik, L. I. The mechanism of the proton transfer: an outline. Biochim. Biophys. Acta - Bioenerg. 1458, 6-27 (2000).

47. Hammes-Schiffer, S. Proton-coupled electron transfer: moving together and charging forward. J. Am. Chem. Soc. 137, 8860-8871 (2015).

48. Layfield, J. P. \& Hammes-Schiffer, S. Hydrogen tunneling in enzymes and biomimetic models. Chem. Rev. 114, 3466-3494 (2014).

49. Markle, T. F., Rhile, I. J. \& Mayer, J. M. Kinetic effects of increased proton transfer distance on proton-coupled oxidations of phenol-amines. J. Am. Chem. Soc. 133, 17341-17352 (2011)

50. Kohen, A. \& Limbach, H.-H. Isotope effects in chemistry and biology, (cRc Press, 2005).

51. Fitzpatrick, P. F. Combining solvent isotope effects with substrate isotope effects in mechanistic studies of alcohol and amine oxidation by enzymes. Biochim. Biophys. Acta (BBA) - Proteins and Proteomics 1854, 1746-1755 (2015).

52. Liu, Y. \& McCrory, C. C. L. Modulating the mechanism of electrocatalytic $\mathrm{CO}_{2}$ reduction by cobalt phthalocyanine through polymer coordination and encapsulation. Nat. Commun. 10, 1683 (2019).

53. Venkatasubban, K. S. \& Schowen, R. L. The Proton Inventory Techniqu. Crit. Rev. Biochem. 17, 1-44 (1984).

54. Krishtalik, L. I. On the Theory of the 'Proton Inventory' Method. Mendeleev Commun. 3, 66-67 (1993)

55. Haddad, A. Z., Cronin, S. P., Mashuta, M. S., Buchanan, R. M. \& Grapperhaus, C. A. Metal-assisted ligand-centered electrocatalytic hydrogen evolution upon reduction of a Bis(thiosemicarbazonato)Cu(II) Complex. Inorg. Chem. 56, 11254-11265 (2017).

56. Chen, Z., Vannucci, A. K., Concepcion, J. J., Jurss, J. W. \& Meyer, T. J. Protoncoupled electron transfer at modified electrodes by multiple pathways. Proc. Natl Acad. Sci. USA 108, E1461-E1469 (2011).

57. Zhang, Y. et al. Pivotal role and regulation of proton transfer in water oxidation on hematite photoanodes. J. Am. Chem. Soc. 138, 2705-2711 (2016).

58. Zhang, Y. et al. Rate-limiting O-O bond formation pathways for water oxidation on hematite photoanode. J. Am. Chem. Soc. 140, 3264-3269 (2018).

59. Bamford, C. H., Tipper, C. F. H. \& Compton, R. G. Electrode Kinetics: Principles and Methodology: Principles and Methodology, (Elsevier, 1986).
60. Wang, L. et al. A nickel (II) PY5 complex as an electrocatalyst for water oxidation. J. Catal. 335, 72-78 (2016).

61. Takashima, T., Ishikawa, K. \& Irie, H. Efficient oxygen evolution on hematite at neutral $\mathrm{pH}$ enabled by proton-coupled electron transfer. Chem. Commun. 52, 14015-14018 (2016).

62. Bediako, D. K., Costentin, C., Jones, E. C., Nocera, D. G. \& Savéant, J.-M. Proton-electron transport and transfer in electrocatalytic films. application to a cobalt-based O2-evolution catalyst. J. Am. Chem. Soc. 135, 10492-10502 (2013).

\section{Acknowledgements}

This work was financially supported by the Fundamental Research Funds for the Central Universities (DUT19LK16), the Natural Science Foundation of China (Grant No. 21120102036, 91233201), the National Basic Research Program of China (973 program, 2014CB239402), the Swedish Research Council (2017-00935), the Swedish Energy Agency, and the K \& A Wallenberg Foundation. We appreciate Dr. Ke Fan from Wuhan University of Technology for helpful suggestions. Open access funding provided by Royal Institute of Technology.

\section{Author contributions}

F.L. and L.S. conceived the project, and wrote the manuscript. W.L. and F.L. performed the most of experiments and analyzed the date. H.Y., X.W., P.Z., and Y.S. helped in experiments and data analyses. All authors discussed the results and commented on the manuscript at all stages.

\section{Competing interests}

The authors declare no competing interests.

\section{Additional information}

Supplementary information is available for this paper at https://doi.org/10.1038/s41467 019-13052-1.

Correspondence and requests for materials should be addressed to F.L. or L.S.

Peer review information Nature Communications thanks the anonymous reviewers for their contributions to the peer review of this work. Peer review reports are available.

Reprints and permission information is available at http://www.nature.com/reprints

Publisher's note Springer Nature remains neutral with regard to jurisdictional claims in published maps and institutional affiliations.

Open Access This article is licensed under a Creative Commons Attribution 4.0 International License, which permits use, sharing, adaptation, distribution and reproduction in any medium or format, as long as you give appropriate credit to the original author(s) and the source, provide a link to the Creative Commons license, and indicate if changes were made. The images or other third party material in this article are included in the article's Creative Commons license, unless indicated otherwise in a credit line to the material. If material is not included in the article's Creative Commons license and your intended use is not permitted by statutory regulation or exceeds the permitted use, you will need to obtain permission directly from the copyright holder. To view a copy of this license, visit http://creativecommons.org/ licenses/by/4.0/

(C) The Author(s) 2019 